\title{
Theoretical determination of kinematic parameters of a nightshade fruit separator
}

\author{
Sergey V. Belousov ${ }^{1, *}$, Sergey Yu. Onikienko ${ }^{1}$, and Nina S. Arakelyan ${ }^{1}$ and Anna I. \\ Belousova $^{1}$ \\ ${ }^{1}$ Federal State Budgetary Educational Institution of Higher Education «Kuban State Agrarian \\ University named after I.T. Trubilin», Krasnodar, Russia
}

\begin{abstract}
Abstact. The work is devoted to the theoretical determination of kinematic parameters of a nightshade fruit separator both in direct and reusable way. The article has a research character, which is expressed in the fact that theoretically the analysis of kinematic parameters of a fruit separator, as well as works of leading scientists on the problem, their shortcomings and ways of solving these problems are indicated. There was determined the main trend of theoretical research. There were also justified the type of the proposed design, its theoretical description and the flow of the technological process. As a result of the work done, the design of the device for reusable harvesting of tomatoes and nightshade vegetables with the proposed working bodies is presented. The conclusions present the main results achieved so far.
\end{abstract}

The main kinematic parameters of the fruit separator include the angular speed of rotation of the rollers and drums. The angular velocity of the drums determines the parameters of the oscillation of the plant, leading to the separation of fruit, and the angular velocity of the rollers should ensure rolling the stem down without slipping. This ensures the integrity of the branches of the plant, suitable for further vegetation.

The angular velocity of the drum is determined from the condition of creating the necessary mode of oscillation of the stems, providing fruit separation due to the inertia forces arising in this case. The angular velocity of the rollers in order to avoid pulling the stems from soil is directed to the side opposite to the rotation of the drum.

Consider the point of the roller A, in contact with the stem in the operation slit of the fruit separator. Together with the roller, it participates in a complex motion: in a portable motion around the center of $\mathrm{O}$ (Figure 1) and relative motion around the center of $\mathrm{O}_{1}$.

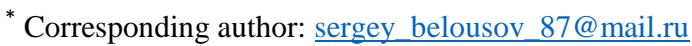




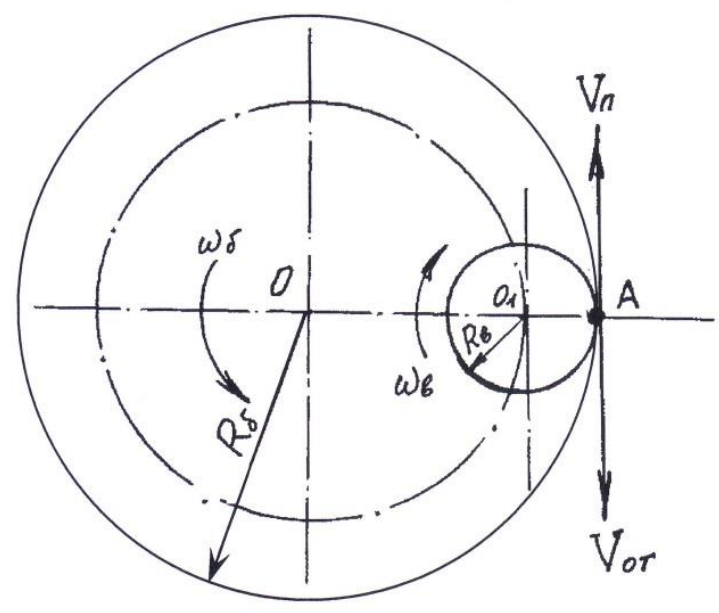

Fig. 1. To determination of the roller's speed

The speed of point $\mathrm{A}$ in portable motion is defined as

$\mathrm{V}_{\mathrm{n}}=\omega_{\sigma} \cdot \mathrm{R}_{\sigma}$,

where $\omega_{6}$ - angular speed of the drum;

$\mathrm{R}_{6}$ - radius of the drum by rollers' circumference.

Velocity of the point $A$ in relative motion will equal to

$\mathrm{V}_{\mathrm{OT}}=\omega_{\mathrm{B}} \cdot \mathrm{R}_{\mathrm{B}}$

where $\omega_{B}$ and $R_{B}$ are velocity and radius of the roller respectively.

The assumption that in the operation slit the roller must be flatted along the stem without slipping, the relative velocity of the drum must be equal to the sum of the portable velocity of movement and speed of rolling, that is

$$
\mathrm{V}_{\text {от }}=V_{n^{+}} V_{n p}
$$

where $V_{n p}$ - velocity of the roller's flatting along the stem.

The value of the rolling speed is determined from the following considerations.

In the process of plants' motion in the fruit separator, fruit remaining uncut on the root, and pass the path,

$\mathrm{S}=\mathrm{L}-\cos \alpha$

At the speed of the device $\mathrm{V}_{\mathrm{M}}$, the stem is in the operation slit of the fruit separator during time $t$, determined from the expression

$$
\mathrm{t}=\frac{L \cdot \cos \alpha}{V_{m}}
$$

During the same time, the part of the stem located above the operation slit should completely roll down, that is, on the other hand, the same time can be expressed as follows:

$$
\mathrm{t}=\frac{H-R_{6}}{V_{n p}}
$$

Equating the right parts of expressions ( 2 and 3 ) we 


$$
\frac{L \cdot \cos \alpha}{V_{m}}=\frac{H-R_{8}}{V_{n p}}
$$

whence

$$
V_{n p}=\frac{V_{m}\left(H-R_{8}\right)}{L \cdot \cos \alpha}
$$

Given that the speed of flatting the rollers on the stem is directed vertically downward, and speeds of the portable and relative motion are in a plane perpendicular to the axes of rollers and drums, we design the found speed of rolling on this plane:

Then

$$
V_{n p}=\frac{V_{m}\left(H-R_{8}\right) \cdot \cos \alpha}{L \cdot \cos \alpha}=\frac{V_{m}\left(H-R_{8}\right)}{L}
$$

Substituting the found value $\mathrm{V}_{\mathrm{np}}$ in the expression (1) we obtain

$$
V_{\text {or }}=\frac{V_{m}\left(H-R_{8}\right)}{L}+\omega+R_{6}
$$

The angular velocity of the rollers in this case will be equal to

$$
\omega_{\mathrm{g}}=\frac{V_{m}\left(H-R_{8}\right)}{L \cdot R_{6}}+\frac{\omega_{6} \cdot R_{6}}{R_{\mathrm{g}}}
$$

And the number of revolutions relative to its own axis is determined from the expression

$$
\mathrm{n}=\frac{30 \cdot \omega_{\mathrm{B}}}{\pi}
$$

where $\omega_{\mathrm{B}}-$ is determined from the expression (7).

Thus, the speed of rotation of rollers of the fruit separator depends on the speed of the harvester, the height of the plant's bushes, design parameters of the drum and rollers and the speed of rotation of the drum.

With known (originally set) parameters, it is determined by the expression (7).

The fruit separator of the harvester consists of two multi-shaft drums rotating in different directions at the same speed.

The rollers on the drums are installed with a displacement relative to each other at an angle that provides vibrations of the stem.

Consider the scheme of occurrence of these oscillations (Figure 2). Denote the angle between the rays radiating from the centers of the drums through $\varphi$. Let us assume that the rollers of the drums are shifted relative to each other by an angle $\varphi / 2$, that is, when the drums rotate, the rollers of one drum move along the center of the inter-roller space of the other one. Consider two positions of the stem in the operation gap - the gap between the drums. 


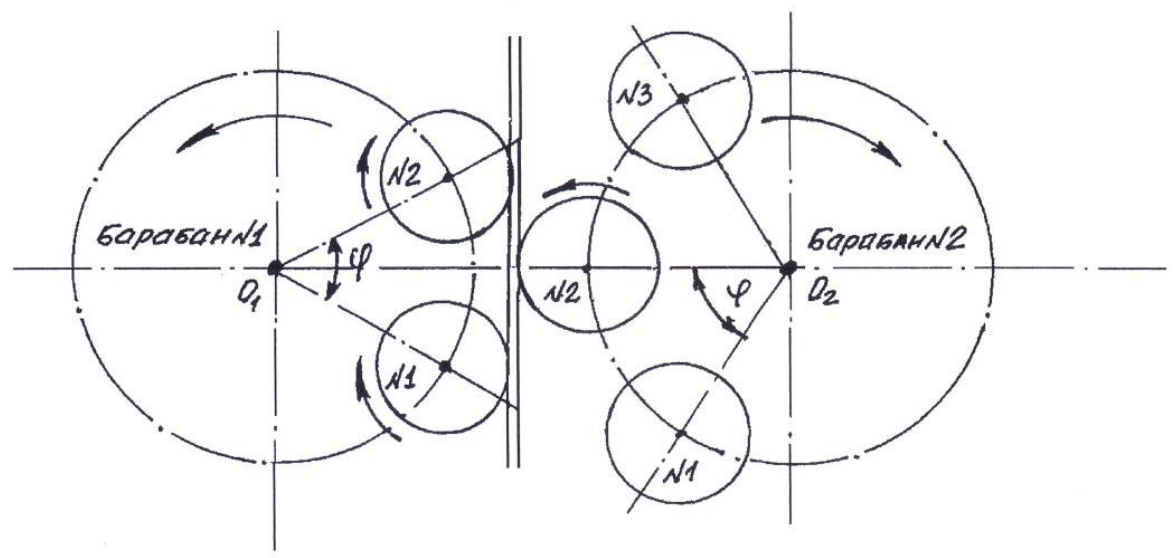

Position 1

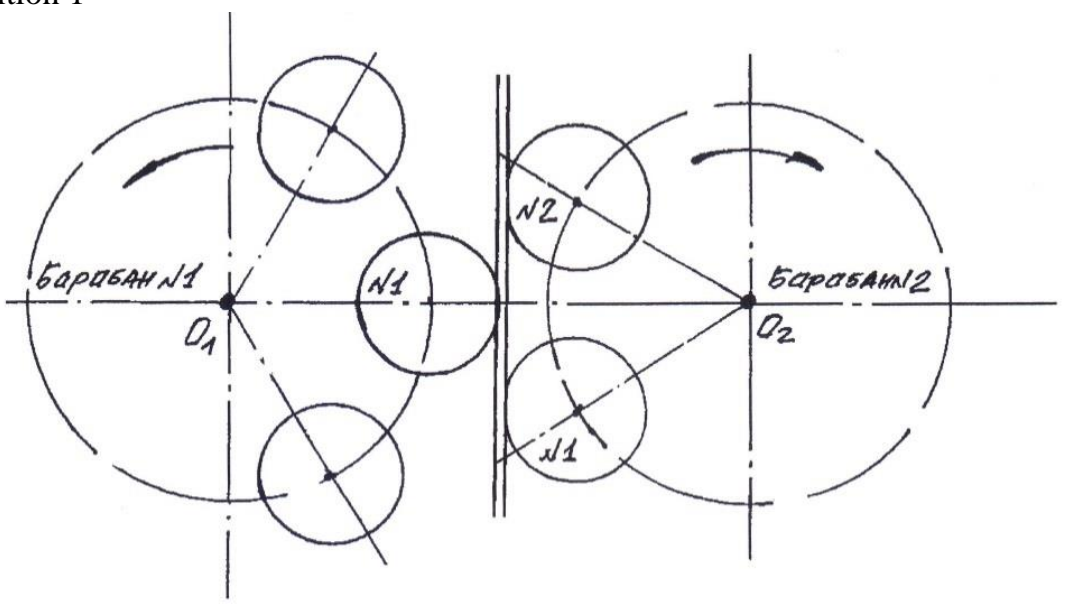

Position 2

Fig. 2. Mechanism of oscillations' occurrence

In position 1, the stem rests on the rollers No.1 and No.2 of the drum No. 1 and presses itself to the drum No.2 of the drum No.2, in this case the axis of which is located on the centers' line of the drums $\mathrm{O}_{1}$ and $\mathrm{O}_{2}$. Turning to the angle $\varphi / 2$ the roller No.1 of the drum No.1 presses the stem to the rollers No.1 and No.2 of the drum No.2. Turning the drums further still at an angle $\varphi / 2$ completes the cycle of oscillation of the stem, which returns to its original position. Therefore, the complete oscillation of the stem will make the angle of rotation of the drums equal to $\varphi$.

Frequency of oscillation.

Depending on the number of rollers on the drum the angle $\varphi$ is determined by the expression

$$
\varphi=\frac{2 \pi}{n}
$$

where $\mathrm{n}$ - numbers of rollers on the drum. 
As shown above, the complete oscillation of the stem makes for the angle of rotation of the drums at an angle $\varphi$, that is, the number of oscillations of the stem per revolution of the drums, is equal to the number of rollers on the drum, that is

$$
\mathrm{n}_{\mathrm{K} о б}=\frac{2 \pi}{\varphi}
$$

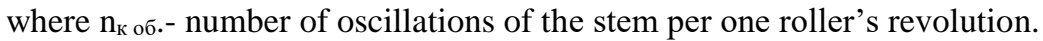

When the number of revolutions of the drum per second is equal to $\mathrm{n}_{\mathfrak{c}}$, the number of oscillations per time unit (in Hertz) is

$$
\mathrm{n}_{\text {кс }}=\mathrm{n}_{\text {к об }} \cdot \mathrm{n}_{\mathrm{c}}
$$

where $\mathrm{n}_{\mathrm{Kc}}$ - number of oscillations per second;

$\mathrm{n}_{\mathrm{c}}-$ number of roller's revolutions per second.

Amplitude of oscillation.

The amplitude of oscillations is determined by the maximum value of the stem movement in the gap between the rollers of the drums. Refer to Figure 3 to determine the amplitude of oscillations.

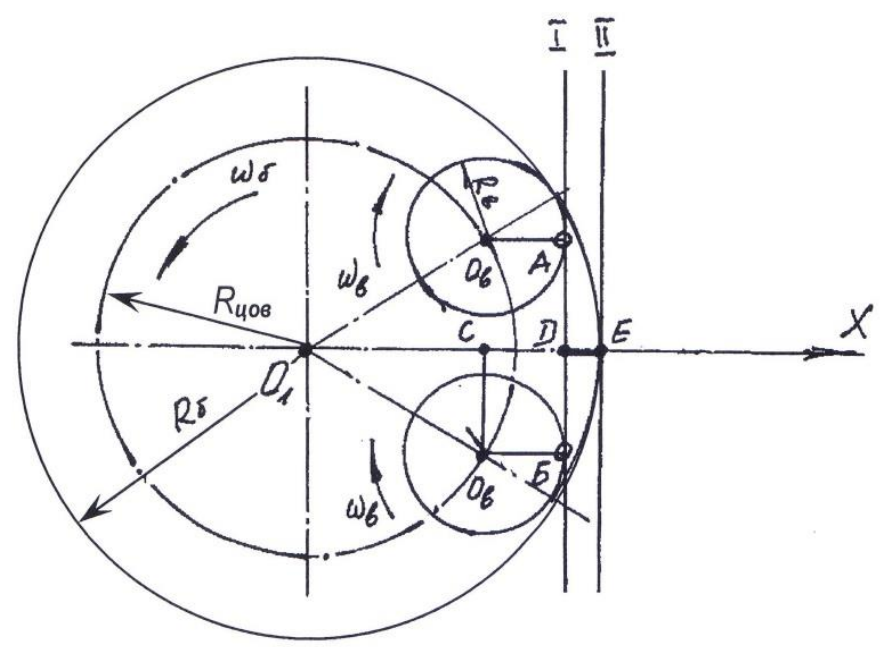

Fig. 3. To determination of the magnitude of the stem oscillation.

Consider the first case. In this position, the stem is in contact with the drum rollers at points $\mathrm{A}$ and $\mathrm{B}$ with further rotation of the drum, the point $\mathrm{A}$ will move away from the stem, and the point $B$ will remove the stem from the original position in the direction of the axis X, coinciding with the direction of the line connecting the centers of the drums' circles. The stem movement will stop at the point $\mathrm{E}$.

Thus, the movement of the stem in one direction (oscillation amplitude) - $\mathrm{S}$ can be expressed as the difference between segments $\mathrm{O}_{1} \mathrm{E}$ and $\mathrm{O}_{1}$ Д.

$\mathrm{S}=\mathrm{O}_{1} \mathrm{E}-\mathrm{O}_{1}$ Д

The segment $0_{1} \mathrm{E}$ is equal to the radius of the drum, which in turn is

$\mathrm{R}_{\text {б }}=\mathrm{R}_{\text {цов }} \mathrm{R}_{\text {в }}$

where $R_{\text {цов }}$-radius of the circumference of the rollers' centers;

$R_{B}$ - radius of the roller.

The segment $\mathrm{O}_{1}$ Д is a sum of segments $\mathrm{O}_{1} \mathrm{C}$ and $\mathrm{CД}$

where 


$$
\mathrm{O}_{1} \mathrm{C}=\mathrm{R}_{\text {цов }}-\cos \varphi / 2 \alpha C Д=\mathrm{R}_{\text {в }}
$$

Consequently,

$$
\mathrm{S}=\mathrm{R}_{\text {цов }}+\mathrm{R}_{\text {в }}-\left(\mathrm{R}_{\text {цов }} \cdot \cos \varphi / 2+\mathrm{R}_{\mathrm{B}}\right)=\mathrm{R}_{\text {цов }}-\mathrm{R}_{\text {цов }} \cdot \cos \varphi / 2
$$

Taking the axis $\mathrm{X}$ as the beginning of the counting of the angle $\mathrm{cp}$ and considering that

$$
\sin (-\alpha)=-\sin \alpha, \operatorname{acos}(-\alpha)=\cos \alpha,
$$

differentiating successively two times $S$ by the angle of rotation $\varphi$, we obtain the speed and acceleration of the stem depending on the angle of rotation

$$
\begin{gathered}
\frac{d S}{d \varphi}=V_{\varphi}=R_{\text {मов }} \cdot \sin \varphi / 2 \\
\frac{d^{2} S}{d \varphi^{2}}=\alpha_{\varphi}=\mathrm{R}_{\text {цОв }} \cdot \cos \varphi / 2
\end{gathered}
$$

The analysis of these expressions shows that at $\varphi=0$ the speed of the stem movement is also zero and the acceleration reaches the maximum value.

Replacing the rotation angle in expression (10) via the angular velocity of the drum $(\omega \mathrm{b})$ and the current time $(\mathrm{t})$, using equality $\varphi / 2=\omega_{\sigma}{ }^{*} \mathrm{t}$, we obtain

$$
\mathrm{S}=\mathrm{R}_{\text {цов }}-\mathrm{R}_{\text {цов }}-\operatorname{cosc} \omega_{6} t
$$

Differentiating the last expression by the variable $t$ allows you to define expressions to determine the speed and acceleration along the path of the stem. In this case, expressions (11) and (12) have the form:

$$
\begin{aligned}
& \frac{d s}{d \varphi}=\mathrm{V}=R_{\text {मов }} \cdot \omega_{6} \sin \omega_{6} t \\
& \frac{d^{2} s}{d \varphi^{2}}=\alpha=R_{\text {मов }} \cdot \cos \omega_{6} t
\end{aligned}
$$

As shown above, the maximum acceleration occurs at $\varphi=0$, i.e.

$$
\alpha_{\max }=\mathrm{R}_{\text {цов }} \cdot \omega_{6}^{2} \cdot \cos \omega_{6} \mathrm{t}
$$

This acceleration creates a force of inertia acting on the fruit at the time of cessation of movement (stop) of the stem.

$$
\mathrm{F}=\mathrm{a} \cdot \mathrm{m}=\mathrm{m} \cdot \mathrm{R}_{\text {цо о в }} \cdot \omega_{6}^{2} \cdot \cos \omega_{6} \mathrm{t}
$$

To separate the fruit, this force must be greater than the strength of the peduncle

$$
\mathrm{F}>\mathrm{P}
$$

where $\mathrm{P}$ - effort necessary for fruit separation

In this case the condition of the fruit separation is 


$$
\mathrm{m} \cdot \mathrm{R}_{\text {цов }} \cdot \omega_{6}^{2}>\mathrm{P}
$$

From the expression (19) we determine the necessary angular velocity of the drum

$$
\omega_{6} \geq \sqrt{\frac{P}{m \cdot R \text { Rूz }}}
$$

where m- mass of separated fruit.

Thus, using expressions (7) and (20), it is possible to determine theoretically the main parameters of the fruit separator, angular velocities of rollers and drums.

In the result of carried out theoretical researches there were obtained the expressions which allow to determine the kinematic parameters of the separator of Solanaceae fruits which will allow more details and better to produce the design of individual operation items of fruit harvesters.

\section{References}

1. Trubilin E.I. Results of experimental studies determining the degree of traction resistance of the plowshare in the treatment of heavy soils / Trubilin E.I., Belousov S.V., Lepshina A.I. // Multidisciplinary network electronic scientific journal of Kuban State Agrarian University. -2014. -No. 103.-P. 673-686.

2. Trubilin E.I. Economic efficiency of the dump soil cultivation developed by a combined plowshare / Trubilin E.I., Belousov S.V., Lepshina A.I. // Multidisciplinary network electronic scientific journal of Kuban State Agrarian University. -2014. -No. 103.-P. 654-672.

3. Trubilin E.I. The main soil cultivation with the formation turnover in modern working conditions and devices for its implementation / Trubilin E.I., Belousov S.V., Lepshina A.I. // Multidisciplinary network electronic scientific journal of Kuban State Agrarian University. -2014. - No. 104.-P. 1902-1922.

4. Belousov S.V. Communication of science and technology in the field of development of machines for basic tillage with the circulation of the bed / Belousov S.V. I/ Multidisciplinary network electronic scientific journal of Kuban State Agrarian University. -2015. No. 109.-P. 468-486.

5. Belousov S.V. Modern technologies of soil cultivation / Belousov S.V. // Scientific provision of Agro-Industrial Complex. -2012. -P. 3-4.

6. Parkhomenko G.G. Improvement of working organs for tillage / Parkhomenko G.G., Bozhko I.V., Semenikhina Y.A., Pantyukhov I.V., Drozdov S.V., Gromakov A.V., Kambulov S.I., Belousov S.V. // State prospects of development of agricultural machinery. Collection of scientific articles of the $9^{\text {th }}$ international scientific and practical conference within the framework of the $19^{\text {th }}$ international agro-industrial exhibition "Interagromash-2016". -2016. -P. 27-30.

7. Belousov S.V. Development of plowshare construction for heavy soil treatment / Belousov S.V., Trubilin E.I. // Science of Kuban. -2013. -No 1.-P. 37-40.

8. Belousov S.V. Patent search for structures that provide soil treatment with the turnover of the reservoir. Method of search. The proposed technical solution / Belousov S.V. // Multidisciplinary network electronic scientific journal of Kuban State Agrarian University. -2015. No. 109.-P. 416-450. 
9. Belousov S.V. Decrease in energy intensity of the process of basic soil processing with turnover of the bed / Belousov S.V. // Fundamental foundations of modern agrarian technologies and technology. Collection of scientific works of the All-Russian Youth Scientific and Practical Conference.- Tomsk National Research Polytechnic University. -2015. -P. 280-283.

10. Belousov S.V. Role and prospects of the development of small-scale mechanization in the context of co-temporary engineering / Belousov S.V. / Scientific support of agroindustrial complex. A collection of scientific articles on the materials of the $72^{\text {nd }}$ Scientific and Practical Conference of pre-applicants on the results of research work for 2016 - 2017.-P. 277-278. 